\title{
AVALIAÇÃO DA QUALIDADE MICROBIOLÓGICA DE ÁGUAS MINERAIS ENVASADAS - DINÂMICA POPULACIONAL DE Pseudomonas aeruginosa
}

\author{
ANELISE TALAMINI IWERSEN* \\ ELISA HIZURU UEMURA YAMANAKA** \\ LUIZ FERNANDO DE LIMA LUZ JÚNIOR*** \\ CRISTINA LEISE BASTOS MONTEIRO****

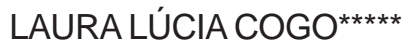

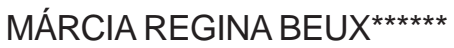

\begin{abstract}
Com o intuito de monitorar alterações no índice de contaminação durante o armazenamento, foram avaliadas quanto à contaminação por Pseudomonas aeruginosa setenta e cinco amostras, de cinco marcas distintas, de água mineral envasadas em copos ou garrafas plásticas de $500 \mathrm{~mL}$ e $1500 \mathrm{~mL}$. Os ensaios foram efetuados em dois períodos diferenciados, o primeiro um dia após aquisição das amostras no ponto de venda e o segundo quando as amostras completaram seis meses de armazenamento. Segundo os padrões determinados pela RDC n. 275/05 do Ministério da Saúde, 53\% dos lotes foram rejeitados. O monitoramento da contaminação durante o armazenamento revelou que, independente da elevação ou redução nas contagens, P.aeruginosa foi detectada mesmo após 180 dias de estocagem, confirmando que se trata de micro-organismo que se adapta em ambientes com baixo teor nutricional. O percentual de rejeição das amostras revelou a necessidade de práticas de higiene mais efetivas a serem adotadas durante o envase, garantindo a comercialização de produtos seguros e que atendam aos rigorosos padrões microbiológicos estabelecidos pela legislação brasileira.
\end{abstract}

PALAVRAS-CHAVE: ÁGUA MINERAL; MICROBIOLOGIA; Pseudomonas aeruginosa.

* Especialista em Gestão da Qualidade e Segurança dos Alimentos, Gerente Técnica dos laboratórios de Microbiologia de Águas e Efluentes e de Microbiologia de Saneantes, Centro de Pesquisa e Procesamento de Alimentos (CEPPA), Curitiba, PR (e-mail: anelise@ufpr.br).

* Farmacêutica, Mestranda, Programa de Pós-Graduação em Microbiologia, Parasitologia, Universidade Federal do Paraná (UFPR), Curitiba, PR (e-mail: cientifico@laborclin.com.br) .

*** Professor, Doutor em Engenharia Química, Programa de Pós-Graduação em Engenharia Química, UFPR, Curitiba, PR (e-mail: luzjr@ufpr.br).

**** Doutora em Biotecnologia, professora de Microbiologia, Departamento de Patologia Básica, UFPR, Cuririba, PR (email: crisleise@gmail.com).

***** Doutora em Biotecnologia, Programa de Pós-Graduação em Processos Biotecnológico, UFPR, Hospital de Clínicas, Cuririba, PR (email: Ilcogo@yahoo.com.br).

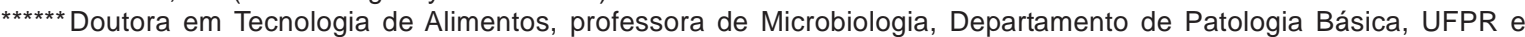
professora do Curso de Farmácia da Pontifícia Universidade Católica do Paraná, Cuririba, PR (e-mail:mrbeux@ufpr.br). 


\section{INTRODUÇÃO}

Água mineral natural consiste na água obtida diretamente de fontes naturais ou por extração de águas subterrâneas (BRASIL, 2005a).

Devido à preocupação com a qualidade dos mananciais e por acreditarem que a água mineral apresenta melhor qualidade, a preferência de muitos consumidores por esse tipo de água tem aumentado em detrimento à água tratada. Com isso, o consumo de água mineral envasada aumentou consideravelmente (SANT'ANA et al., 2003). Em 10 anos, a produção de água mineral no Brasil aumentou 4,1 bilhões de litros (ABINAM, 2007).

Doenças causadas pelo consumo de águas envasadas são raras, no entanto surtos causados pelo consumo de águas envasadas contaminadas vêm sendo rastreados. O incidente mais conhecido ocorreu durante o surto de cólera em Portugal em 1974, quando o Vibrio cholerae foi isolado de duas nascentes que forneciam água para uma indústria envasadora. Embora a água fosse originária de fonte considerada limpa, aparentemente foi contaminada pela infiltração de esgoto através do estrato calcário (ROSENBERG, 2003).

A ocorrência de distúrbios gastrintestinais seguintes ao consumo de águas minerais tem revelado que amostras coletadas diretamente do aquífero apresentam população bacteriana de aproximadamente $10-10^{2} \mathrm{UFC} / \mathrm{mL}$ e que essa população aumenta para aproximadamente $10^{3}$ a $10^{6} \mathrm{UFC} / \mathrm{mL}$ após o envase (JAYASEKARA et al., 1998).

O rápido crescimento bacteriano após o envase pode ser causado pela oxigenação da água, pelo aumento da superfície de contato (frasco), pela elevação da temperatura durante o armazenamento e pelos vestígios de nutrientes liberados pela garrafa (VENIERI et al., 2006).

Levantamentos realizados em águas minerais envasadas em diferentes países têm demonstrado que P.aeruginosa é o micro-organismo predominantemente encontrado. Essa espécie, patógeno em potencial, contamina a água tanto por ser autóctone e estar largamente distribuída no ambiente, como por falhas no processo de envase (JAYASEKARA et al., 1998).

A P.aeruginosa tem sido encontrada em águas minerais originárias do Brasil, Canadá, França, Alemanha, Espanha, Estados Unidos e outros países. Sua presença pode indicar contaminação associada à infiltração natural, matéria fecal humana, efluentes domésticos e agroindustriais ou falhas no processo de higienização. As contaminações durante o envase podem ser resultado de colonização dos equipamentos devido a defeitos nas vedações de borracha ou arruelas, graxa contendo compostos orgânicos e emprego de sabão por fornecer nutrientes para esse contaminante (WARBURTON, 1993).

Ranhuras presentes na face interna de embalagens retornáveis de água mineral e equipamentos destinados a sua higienização e envase podem ser locais propícios para o desenvolvimento de biofilmes e a consequente contaminação da água (FARD, 2007).

A aderência às superfícies internas das embalagens pode explicar a longa sobrevivência de bactérias autóctones na água mineral e com isso a produção de defeitos como odor e manchas. Esses micro-organismos podem sobreviver em águas envasadas por vários anos (JAYASSEKARA et al., 1999).

A preocupação com a presença de P.aeruginosa nas águas minerais reside no fato de serem patógenos oportunistas, causadores de infecções em indivíduos imunocomprometidos, recém-nascidos e idosos. Além disso, muitas linhagens de P.aeruginosa são resistentes a antibióticos (SANT'ANA et al., 2003).

O objetivo desse trabalho foi avaliar a qualidade da água mineral envasada comercializada nas redes de distribuição da cidade de Curitiba (Paraná) quanto à presença de $P$. aeruginosa conforme parâmetros estabelecidos pela RDC n. 275/05 do Ministério da Saúde e monitorar as contagens de P.aeruginosa durante o período de sua validade, avaliando-se a influência do armazenamento.

\section{MATERIAL E MÉTODOS}

Foram selecionados três tipos de embalagens de água mineral (copos plásticos, garrafas 
plásticas de $500 \mathrm{~mL}$ e $1500 \mathrm{~mL}$ ) provenientes de cinco marcas distintas, sendo três da região de Curitiba, uma de Morretes e outra do estado de Santa Catarina. Todas as unidades da mesma marca foram adquiridas no mesmo ponto de venda e as do mesmo tipo de embalagem de cada marca com a mesma data de envase. Para cada marca e embalagem foram adquiridas cinco unidades.

As contagens de $P$.aeruginosa foram realizadas em duas etapas, denominadas de tempo zero $\left(T_{0}\right)$ e tempo um $\left(T_{1}\right)$. No tempo zero, os ensaios foram realizados um dia após a aquisição das amostras no ponto de venda e no tempo um, quando as mesmas completaram seis meses de armazenamento. Esse período corresponde ao prazo de validade das garrafas de $500 \mathrm{~mL}$ e $1500 \mathrm{~mL}$ da Marca A, dos copos da Marca C e da metade do período de validade das demais amostras.

As contagens de $P$.aeruginosa foram realizadas segundo a técnica dos tubos múltiplos com diluição, descrita no Standard methods for the examination of water and wastewater (APHA, 2005).

Efetuou-se a avaliação da qualidade da água mineral segundo padrões microbiológicos presentes na RDC no 275 (BRASIL, 2005b), sendo a avaliação do período de armazenamento realizada pela diferença logarítmica entre T1 e To.

\section{RESULTADOS E DISCUSSÃO}

A contagem de P.aeruginosa (NMP/100mL) nos tempos $\mathrm{T}_{0}$ e $\mathrm{T}_{1}$ está apresentada no Quadro 1.

QUADRO 1 - CONTAGEM DE Pseudomonas aeruginosa NMP/100 mL NOS To E T1

\begin{tabular}{|c|c|c|c|c|c|c|c|}
\hline $\begin{array}{c}\text { Tipo } \\
\text { Embalagem }\end{array}$ & AMOSTRA & ETAPAS & MARCAA & MARCA B & MARCA C & MARCA D & MARCA E \\
\hline \multirow{10}{*}{$\begin{array}{l}\text { O } \\
\text { O̊ } \\
\text { U }\end{array}$} & \multirow{2}{*}{1} & $\mathbf{T}_{0}$ & $<1,8$ & $<1,8$ & $2,4 \times 10^{3}$ & $<1,8$ & $<1,8$ \\
\hline & & $\mathbf{T}_{1}$ & $<1,8$ & $<1,8$ & $3,5 \times 10^{2}$ & $<1,8$ & $<1,8$ \\
\hline & \multirow[t]{2}{*}{2} & $\mathbf{T}_{0}$ & $<1,8$ & $<1,8$ & $9,2 \times 10^{2}$ & $<1,8$ & $<1,8$ \\
\hline & & $\mathrm{T}_{1}$ & $<1,8$ & $<1,8$ & $2,2 \times 10^{2}$ & $<1,8$ & $<1,8$ \\
\hline & \multirow[t]{2}{*}{3} & $\mathbf{T}_{0}$ & $<1,8$ & 1,8 & $1,6 \times 10^{3}$ & $<1,8$ & $1,6 \times 10^{3}$ \\
\hline & & $\mathbf{T}_{1}$ & $<1,8$ & $<1,8$ & $9,2 \times 10^{2}$ & $<1,8$ & $3,5 \times 10^{2}$ \\
\hline & \multirow{2}{*}{4} & $\mathbf{T}_{0}$ & $<1,8$ & $<1,8$ & $9,2 \times 10^{2}$ & $2,4 \times 10^{3}$ & $<1,8$ \\
\hline & & $\mathrm{T}_{1}$ & $<1,8$ & $<1,8$ & $1,6 \times 10^{3}$ & $1,7 \times 10^{2}$ & $<1,8$ \\
\hline & \multirow[t]{2}{*}{5} & $\mathbf{T}_{0}$ & $<1,8$ & $<1,8$ & $2,4 \times 10^{3}$ & $<1,8$ & $<1,8$ \\
\hline & & $\mathbf{T}_{1}$ & $<1,8$ & $<1,8$ & $1,6 \times 10^{3}$ & $<1,8$ & $<1,8$ \\
\hline \multirow{10}{*}{ 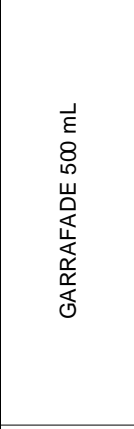 } & \multirow{2}{*}{1} & $\mathbf{T}_{0}$ & $<1,8$ & $<1,8$ & 7,8 & $<1,8$ & 9,3 \\
\hline & & $\mathbf{T}_{1}$ & $<1,8$ & $<1,8$ & 7,8 & $<1,8$ & $5,4 \times 10^{3}$ \\
\hline & \multirow[t]{2}{*}{2} & $\mathbf{T}_{0}$ & $<1,8$ & $<1,8$ & 2,0 & $<1,8$ & 4,0 \\
\hline & & $\mathbf{T}_{1}$ & $<1,8$ & $<1,8$ & $<1,8$ & $<1,8$ & $2,2 \times 10^{2}$ \\
\hline & \multirow[t]{2}{*}{3} & $\mathbf{T}_{0}$ & $<1,8$ & $<1,8$ & $<1,8$ & $<1,8$ & $<1,8$ \\
\hline & & $\mathrm{T}_{1}$ & $<1,8$ & $<1,8$ & $<1,8$ & $<1,8$ & $1,6 \times 10^{3}$ \\
\hline & \multirow[t]{2}{*}{4} & $T_{0}$ & $<1,8$ & $<1,8$ & 2,0 & $<1,8$ & 4,5 \\
\hline & & $\mathbf{T}_{1}$ & $<1,8$ & $<1,8$ & $<1,8$ & $<1,8$ & $2,4 \times 10^{3}$ \\
\hline & \multirow[t]{2}{*}{5} & $\mathbf{T}_{0}$ & $<1,8$ & $<1,8$ & 4,0 & $<1,8$ & 4,5 \\
\hline & & $\mathrm{T}_{1}$ & $<1,8$ & $<1,8$ & $3,3 \times 10$ & $<1,8$ & $4,9 \times 10$ \\
\hline \multirow{10}{*}{ 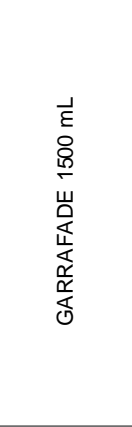 } & \multirow[t]{2}{*}{1} & $\mathbf{T}_{0}$ & $<1,8$ & $<1,8$ & 4,5 & 23 & $5,4 \times 10^{2}$ \\
\hline & & $\mathbf{T}_{1}$ & $<1,8$ & $<1,8$ & $2,4 \times 10^{3}$ & $4,8 \times 10$ & $9,2 \times 10^{2}$ \\
\hline & \multirow[t]{2}{*}{2} & $\mathbf{T}_{0}$ & $<1,8$ & $<1,8$ & 2,0 & $1,6 \times 10^{3}$ & $9,2 \times 10^{2}$ \\
\hline & & $\mathbf{T}_{1}$ & $<1,8$ & $<1,8$ & $2,4 \times 10^{3}$ & $1,6 \times 10^{3}$ & $2,4 \times 10^{2}$ \\
\hline & \multirow[t]{2}{*}{3} & $\mathbf{T}_{0}$ & $<1,8$ & $<1,8$ & $<1,8$ & 17 & $5,4 \times 10^{2}$ \\
\hline & & $\mathrm{T}_{1}$ & $<1,8$ & $<1,8$ & $1,7 \times 10^{2}$ & $2,1 \times 10$ & $1,3 \times 10^{2}$ \\
\hline & \multirow[t]{2}{*}{4} & $\mathbf{T}_{0}$ & $<1,8$ & $<1,8$ & $<1,8$ & 20 & $7,9 \times 10$ \\
\hline & & $\mathbf{T}_{1}$ & $<1,8$ & $<1,8$ & $<1,8$ & $3,4 \times 10$ & $4,9 \times 10$ \\
\hline & \multirow[t]{2}{*}{5} & $\mathbf{T}_{0}$ & $<1,8$ & $<1,8$ & $<1,8$ & 24 & 7,8 \\
\hline & & $\mathbf{T}_{1}$ & $<1,8$ & $<1,8$ & $7,9 \times 10$ & $1,3 \times 10^{2}$ & $1,6 \times 10^{3}$ \\
\hline
\end{tabular}


Oito dos quinze lotes analisados foram reprovados, representando índice de rejeição de 53\%.

Deve-se ressaltar que três das cinco marcas testadas foram rejeitadas. As marcas $\mathrm{C}$ e $\mathrm{E}$ apresentaram contagens superiores ao limite estabelecido pela legislação brasileira nos três tipos de embalagens e a marca $D$, apesar de não ter apresentado crescimento em nenhuma das garrafas de $500 \mathrm{~mL}$, foi rejeitada nos outros dois tipos de embalagens (garrafas de $1.500 \mathrm{~mL}$ e copos). Tal fato indica que a contaminação das três marcas de água mineral independe do tipo de embalagem.

Quanto à dinâmica populacional, os resultados demonstraram que nos copos houve redução do crescimento de $P$.aeruginosa entre a primeira análise $\left(T_{0}\right)$ e a análise posterior $\left(T_{1}\right)$. No entanto, as garrafas de $500 \mathrm{~mL}$ e de $1500 \mathrm{~mL}$ apresentaram acréscimo nas contagens entre os $\mathrm{T}_{0}$ e $\mathrm{T}_{1}$ (Figura 1).

\section{FIGURA 1- DINÂMICA POPULACIONAL DE P.aeruginosa NO TEMPO ZERO (To) E TEMPO UM (T1)-log 10}

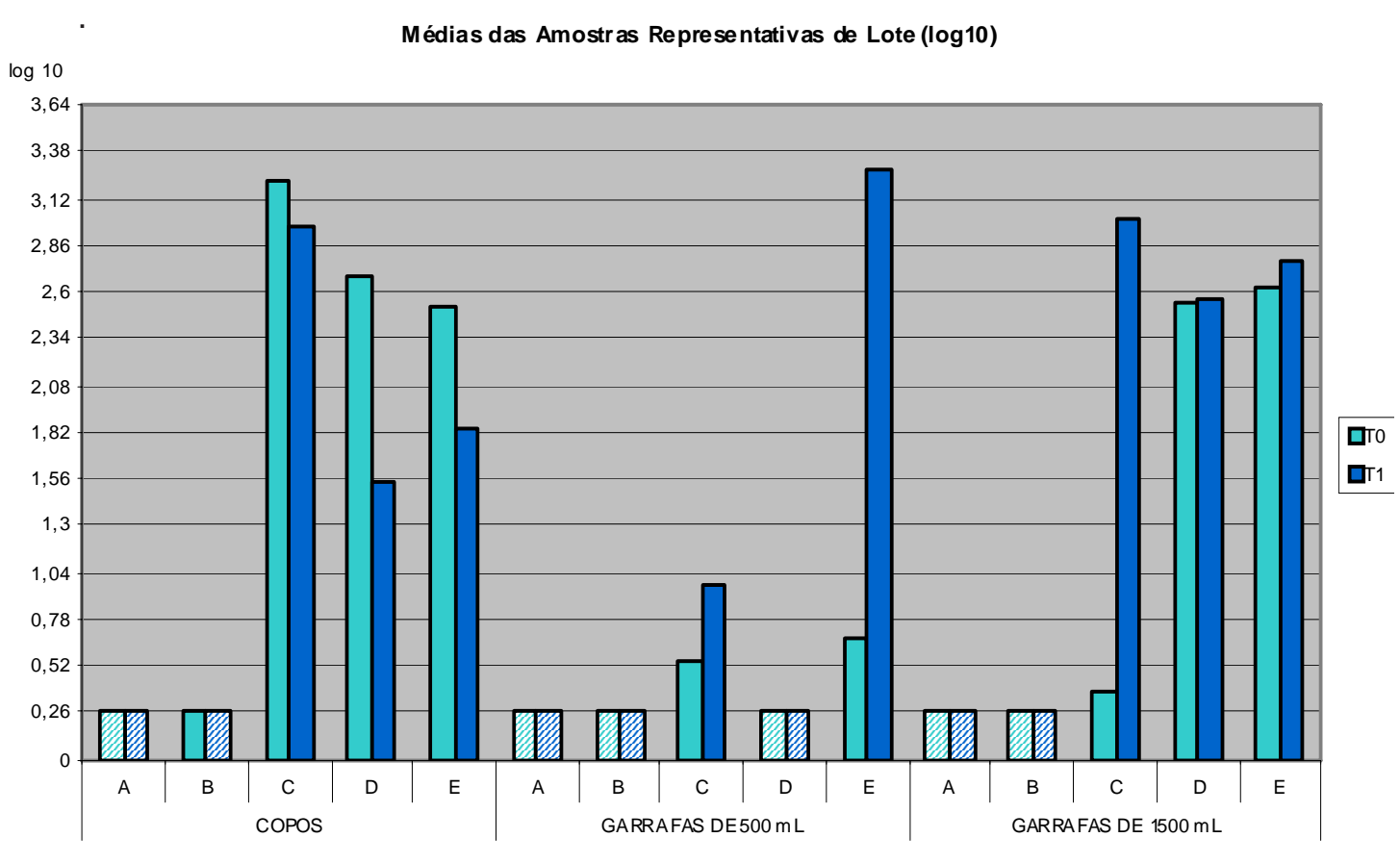

Valores de $\log =<0,26$

As análises dos copos no $T_{0}$ foram realizadas entre 70 e 95 dias após a data de envase, e nesse período a concentração bacteriana poderia estar passando da fase de crescimento para a fase de declínio. Já nas amostras das garrafas de 500 e $1500 \mathrm{~mL}$, as análises foram realizadas entre 30 e 60 dias da data de envase, podendo-se supor que os micro-organismos ainda estavam em fase de crescimento lento, aumentando suas contagens após esse período.

LEGNANI et al. (1999) em 5 anos de estudo sobre a curva de crescimento de duas estirpes de $P$.aeruginosa relataram que as duas cepas apresentaram curta fase exponencial e rápido crescimento no período logo após sua inoculação, com tempo de duplicação de aproximadamente 48 horas. Evidenciaram ainda que o período das contagens mais altas ocorreu entre 7 e 70 dias após a inoculação, seguido por fase de gradual declínio.

A importância dos resultados das comparações reside no fato de que mesmo após 180 dias de armazenamento, sob condições adequadas, foram observadas contagens de P.aeruginosa em níveis bastante preocupantes para a saúde e integridade do consumidor em três das marcas de água mineral adquiridas em Curitiba. 
Segundo JAYASSEKARA et al. (1999), as bactérias autóctones podem sobreviver em águas envasadas por vários anos, havendo a possibilidade de ocorrer ainda crescimento secundário porque algumas espécies morrem e fornecem nutrientes para outras espécies.

TAMAGNINI E GONZÁLEZ (1997) observaram que após 30 dias de armazenamento a P.aeruginosa tornou-se predominante sobre a microbiota aeróbica acompanhante nas amostras de águas testadas. Estudos sugerem também que contaminantes orgânicos associados ao plástico (PVC, PET) no qual são fabricadas as embalagens, podem constituir fonte de nutrientes para esses microrganismos (JAYASSEKARA et al., 1998). Além disso, WARBURTON (1994) evidenciou em seus estudos que a presença desse micro-organismo em águas minerais envasadas potencializa a sobrevivência de Aeromonas, salmonelas e possivelmente outros patógenos, aumentado a preocupação referente à presença dessas bactérias em águas engarrafadas.

\section{CONCLUSÃO}

Os resultados obtidos na avaliação da qualidade da água mineral envasada revelaram que pelo menos quanto ao parâmetro da P.aeruginosa, o período de armazenamento torna-se irrelevante. Isso se deve aos rígidos limites estabelecidos pela legislação, em que as águas analisadas, mesmo apresentando grandes variações nas contagens entre os $\mathrm{T}_{0} \mathrm{e} \mathrm{T}_{1}$, foram rejeitadas nas duas etapas da análise. Mediante essas afirmações, fica evidente que a legislação brasileira prima pela implantação de práticas adequadas de higiene com a consequente comercialização de águas minerais envasadas de boa qualidade.

O monitoramento das alterações que ocorreram nas contagens de P. aeruginosa revelou que dependendo da época em que as análises são realizadas podem ser encontradas concentrações variáveis. No entanto, independente da redução ou crescimento entre $T_{0}$ e $T_{1}$, as amostras ainda apresentaram contagens elevadas após 180 dias de armazenamento, representando preocupação referente à saúde e integridade do consumidor.

\section{ABSTRACT \\ EVALUATION OF BOTTLED MINERAL WATER MICOBIOLOGICAL QUALITY - POPULATION DYNAMICS OF Pseudomonas aeruginosa}

Aiming to monitor alterations in the contamination index during storage seventy-five samples, of five distinct brands, of mineral water bottled in cups or plastic bottles of $500 \mathrm{~mL}$ and $1500 \mathrm{~mL}$ have been evaluated for contamination by Pseudomonas aeruginosa. This assessment was conducted in two different periods; the first period was one day after acquiring the samples and the second when the samples completed six months of storage. According to the standards determined by RDC n 275/05 of the Health Ministry (Brazil), $53 \%$ of the lots were rejected. The monitoring of the contamination during storage revealed that regardless of some samples have shown growth and other reduction in counts, the Pseudomonas aeruginosa was present, even after 180 days of storage, confirming that it is a microorganism that can fit in nutritionally poor environments. These rejection rates of the samples revealed the need to adopt more appropriate hygiene practices, in order to get safe products which attend to the strict microbiological standards established by the Brazilian legislation.

KEY-WORDS: MINERAL WATER; MICROBIOLOGY; Pseudomonas aeruginosa.

\section{REFERÊNCIAS}

1 ABINAM. Associação Brasileira da Indústria de Águas Minerais. Portal das águas minerais brasileiras. Disponível em: <http://www.abinam.com.br/site/legislacao.asp> Acesso em: 22 set. 2007.

2 APHA. American Public Health Association. Standard methods for the examination of water and wastewater. $21^{\text {St }}$ ed. Washington, 2005. 
3 BRASIL. Ministério da Saúde. Agência Nacional de Vigilância Sanitária. Resolução RDC n 274 de 22 de setembro de 2005. Regulamento técnico para águas envasadas e gelo. Diário Oficial [da] República Fedrativa do Brasil, Brasília, 23 de setembro de 2005 (a).

4 BRASIL. Ministério da Saúde. Agência Nacional de Vigilância Sanitária. Resolução RDC $n^{\circ} 275$ de 22 de setembro de 2005. Regulamento técnico de características microbiológicas para água mineral natural e água natural. Diário Oficial [da] República Fedrativa do Brasil, Brasília, 23 de setembro de 2005 (b).

5 FARD, E.M.G.P. Avaliação da qualidade da água mineral e do processo de envase em duas fontes comerciais. Curitiba, 2007. 96 p. Dissertação (Mestrado em Tecnologia de Alimentos), Universidade Federal do Paraná.

6 JAYASEKARA, N.Y.; HEARD, G.M.; COX, J.M.; FLEET, G.H. Association of micro-organisms with the inner surfaces of bottles of non-carbonated mineral waters. Food Microbiology, v. 16, p. 115-128, 1999.

7 JAYASEKARA, N.Y.; HEARD, G.M.; COX, J.M.; FLEET, G.H. Populations of pseudomonads and related bacteria associated with bottled non-carbonated mineral water. Food Microbiology, v. 15, p. 167-176, 1998.

8 LEGNANI, P.; LEONI, E.; RAPUANO, S.; TURIN, D.; VALENTI, C. Survival and growth of Pseudomonas aeruginosa in natural mineral water: a 5-year study. International Journal of Food Microbiology, v. 53, p. 153-158, 1999.

9 ROSEnBERG, F.A. The microbiology of bottled water. Clinical Microbiology Newsletter, v. 25, n. 6, p. 41-44, 2003.

10 SANT'ANA, A.S.; SILVA, S.C.F.L.; FARANI, I.O.J.R; AMARAL, C.H.R.; MACEDO, F.V. Qualidade microbiológica de águas minerais. Ciência e Tecnologia de Alimentos, v.23, p.190-194, 2003.

11 TAMAGNINI, L.M; GONZÁLEZ, R.D. Bacteriological stability and growth kinetics of Pseudomonas aeruginosa in bottled water. Journal of Applied Microbiology, v. 83, p. 91-94, 1997.

12 VENIERI, D.; VANTARAKIS, A.; KOMNINOU, G.; PAPAPETROPOULOU, M. Microbiological evaluation of bottled noncarbonated ("still") water from domestic brands in Greece. International Journal of Food Microbiology, v. 107, p. 68-72, 2006.

13 WARBURTON, D. W. A review of the microbiological quality of bottled water sold in Canada. Part 2 . The need for more stringent standards and regulations. Canadian Journal of Microbiology, v. 39, n. 2, p. 158-168, 1993.

14 WARBURTON, D. W.; BOWEN, B.; KONKLE, A. The survival and recovery of Pseudomonas aeruginosa and its effect upon salmonellae in water: methodology to test bottled water in Canada. Canadian Journal of Microbiology, v. 40, n. 12 , p. 987-992, 1994. 